Polymer Journal, Vol. 5, No. 1, pp 41-48 (1973)

\title{
Dielectric Behaviour of Some Vinyl-Type Polymers in Dilute Solution
}

\author{
Satoru Mashimo and Akio Chiba \\ Department of Applied Physics, School of Science and Engineering, \\ Waseda University, Shinjuku-ku, Tokyo, Japan.
}

(Received December 25, 1972)

\begin{abstract}
Dielectric loss measurements using frequencies from 1 to $150 \mathrm{MHz}$ were carried out on four vinyl-type polymers in dilute solutions (PVC, $\mathrm{P} p \mathrm{CS}, \mathrm{PpBS}$, and PVAc in toluene, dioxane, and carbon tetrachloride) at temperatures from $-23^{\circ}$ to $60^{\circ} \mathrm{C}$. The shape of the absorption curve is always asymmetric, irrespective of the kind of polymer, molecular weight of the polymer, solvent, and temperature. The relaxation time has no molecular-weight dependence. It does, however, depend on the solvent, and is approximately proportional to the solvent viscosity. The activation energy, $\Delta H_{\mathrm{A}}$ is $3.2-$ $5.9 \mathrm{kcal} / \mathrm{mol}$ for each solution, and depends on that of the solvent viscosity, $\Delta H_{\eta}$, in the manner described by $\Delta H_{\mathrm{A}}=\Delta H_{\eta}+C$, where $C$ is a constant. $C$ is proposed to represent the potential energy for the conformational change. It is also proposed that two relaxation mechanisms, a diffusion-controlled mechanism for segmental rotation and a site model, should be taken into consideration simultaneously in order to interpret the dielectric behaviour.
\end{abstract}

KEY WORDS Dielectric Absorption / Dilute Solution / Solvent Viscosity / Relaxation Time / Activation Energy / Shape of Absorption Curve / Kramers' Theory / Frictional Coefficient / Barrier Energy /

Polar polymers with dipoles rigidly and perpendicularly attached to the chain backbone offer a very interesting example for polymer studies, since the change in the direction of the dipole requires a change in the conformation of the chain backbone. Dielectric measurements on dilute solutions of such polymers will, therefore, offer important information on the chain motion. The influences of solvent viscosity and temperature on the dielectric properties are of particular interest, since it is expected that the effects of these variables are directly connected with dipolar relaxation mechanisms. If the dipolar relaxation is rotationary diffusion-controlled and if Stokes law is applicable, the effect of the solvent viscosity will be dominant. If the dipolar relaxation is caused by the transition of dipoles between two or more sites, the relaxation time and the activation energy will not depend much on the solvent viscosity. Furthermore, when the number of sites more than three, the shape of the absorption curve will change as the temperature varies. $^{1,2}$
Though some reports concerning the dielectric absorption of polymers having perpendicular dipoles in dilute solutions were already presented, ${ }^{3,4}$ data concerning the effect of the solvent viscosity and temperature and data in the high frequency region are insufficient to discuss the above problems.

In the present investigation dielectric losses of poly(vinyl chloride)(PVC), poly( $p$-chlorostyrene)(P $p C S)$, poly $(p$-bromostyrene $)(\mathbf{P} p \mathbf{B S})$, and poly(vinyl acetate)(PVAc) in dilute solutions in nonpolar solvents (toluene, dioxane, and carbon tetrachloride) were measured over a wide temperature range of $-23-60^{\circ} \mathrm{C}$ using high frequencies from $1 \mathrm{MHz}$ up to $150 \mathrm{MHz}$. Furthermore, the effects of the solvent viscosity and the temperature are investigated in detail. Some dielectric relaxation mechanisms are discussed in relation to the experimental results and a suggestion for theoretical treatment is presented.

\section{EXPERIMENTAL}

Five samples of PVAc of different molecular 
weight were provided by Sekisui Chemical Co., Ltd. The number-average molecular weight of these samples was $0.79 \times 10^{4}, 0.97 \times 10^{4}, 3.04 \times 10^{4}$, $10.97 \times 10^{4}$, and $16.34 \times 10^{4}$, respectively. Molecular weight of the sample of the lowest molecular weight was determined by vapourpressure osmometer, and the others by membrane high-speed osmometer. Four sample of PVC were provided by Shin-etsu Chemical Industry Co., Ltd. The number-average molecular weight was $6.3 \times 10^{3}, 1.3 \times 10^{4}, 2.5 \times 10^{4}$, and $1.6 \times 10^{5}$, respectively. One sample of PVC with the numberaverage molecular weight $4.4 \times 10^{4}$ was provided by Denki Kagaku Kogyo Co., Ltd. Two samples of $\mathrm{P} p \mathrm{CS}$ were prepared by thermal-polymerization in our laboratory, the weight-average molecular weights of which were $8.6 \times 10^{4}$ and $4.7 \times 10^{5}$. The molecular weights of $\mathrm{PVC}$ and $\mathrm{P} p \mathrm{CS}$ were determined by viscosity measurements by using relationships between the molecular weight and the limiting viscosity number..$^{5,6}$ One sample of $\mathrm{P} p \mathrm{BS}$ was prepared also in our laboratory by thermal-polymerization. Its limiting viscosity number in benzene at $25^{\circ} \mathrm{C}$ was 0.28 .

The solvents used in the present investigation were toluene, dioxane, and carbon tetrachloride, which were dehydrated and distilled before use. All solutions were prepared by weighing both components.

Dielectric constant and loss were measured at frequencies from 1 to $150 \mathrm{MHz}$ with a 301D Twin$\mathrm{T}$ bridge manufactured by Fujisoku Electric Co., Ltd. This bridge is essentially an inpedancemeasuring circuit devised by Sinclair and Wood. ${ }^{7}$ The bridge was first balanced with air or dry nitrogen gas in the sample cell so that the current is zero at the detector and then balanced again after pouring the solution into the cell. The dielectric constant $\varepsilon^{\prime}$ and loss factor $\varepsilon^{\prime \prime}$ for a solution can be evaluated from the difference between these two balance points of the bridge. The oscillator (Type S-163B6) and the detector (Type DA-202A) were manufactured by Fujisoku Electric Co., Ltd. The error in the measurement was less than $\pm \mathbf{0 . 0 0 2}$ for the constant and $\pm \mathbf{0 . 0 0 0 3}$ for the loss factor.

\section{RESULTS}

A typical example of the results of the dielectric

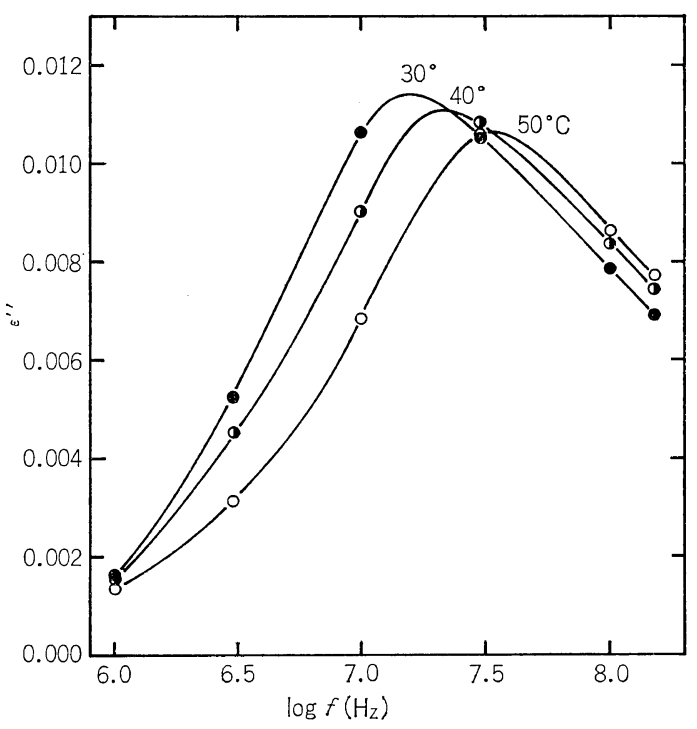

Figure 1. Frequency dependence of dielectric loss at various temperatures for $2.09-\%$ dioxane solution of $\mathrm{P} p \operatorname{CS}\left(\bar{M}_{w}=8.6 \times 10^{4}\right)$.

absorption measurements is shown in Figure 1. The curve shifts to the higher frequency region and the value of maximum loss decreases as the temperature rises. The curve is asymmetric, being broader on the high frequency side.

The absorption-curve shapes may be compared with each other by plotting the reduced loss $\left(\varepsilon^{\prime \prime} / \varepsilon_{\max }^{\prime \prime}\right)$ against $\log \left(f / f_{m}\right)$, where $f_{m}$ is the frequency corresponding to the maximum loss $\varepsilon_{\max }^{\prime \prime}$. Figure 2 shows the reduced plots for PVC in dioxane, $\mathrm{P} p \mathrm{CS}$ in toluene and dioxane, $\mathrm{P} p \mathrm{BS}$ in toluene and dioxane, and PVAc in toluene, dioxane, and carbon tetrachloride. Exactly the same curve was obtained for all solutions. The value of Kirkwood's distribution parameter, ${ }^{8}$ $H_{m}=\varepsilon_{\max }^{\prime \prime} /\left(\varepsilon_{0}{ }^{\prime}-\varepsilon_{\infty}{ }^{\prime}\right)$, obtained from a Cole-Cole plot was $0.31 \pm 0.01$, where $\varepsilon_{0}^{\prime}$ and $\varepsilon_{\infty}^{\prime}$ are the low- and high-frequency dielectric constants, obtained as the intercepts on the abscissa of the Cole-Cole plot.

The principal results obtained for relaxation time and maximum loss, and also some derived quantities, are shown in Tables I-IV. It was found that the relaxation time $\tau\left(=1 / 2 \pi f_{m}\right)$ is fairly independent of the molecular weight of the polymer. It can also be seen that $f_{m}$ increases as the temperature increases. The apparent activation energy $\Delta H_{\mathrm{A}}$ listed in Tables I-IV was 


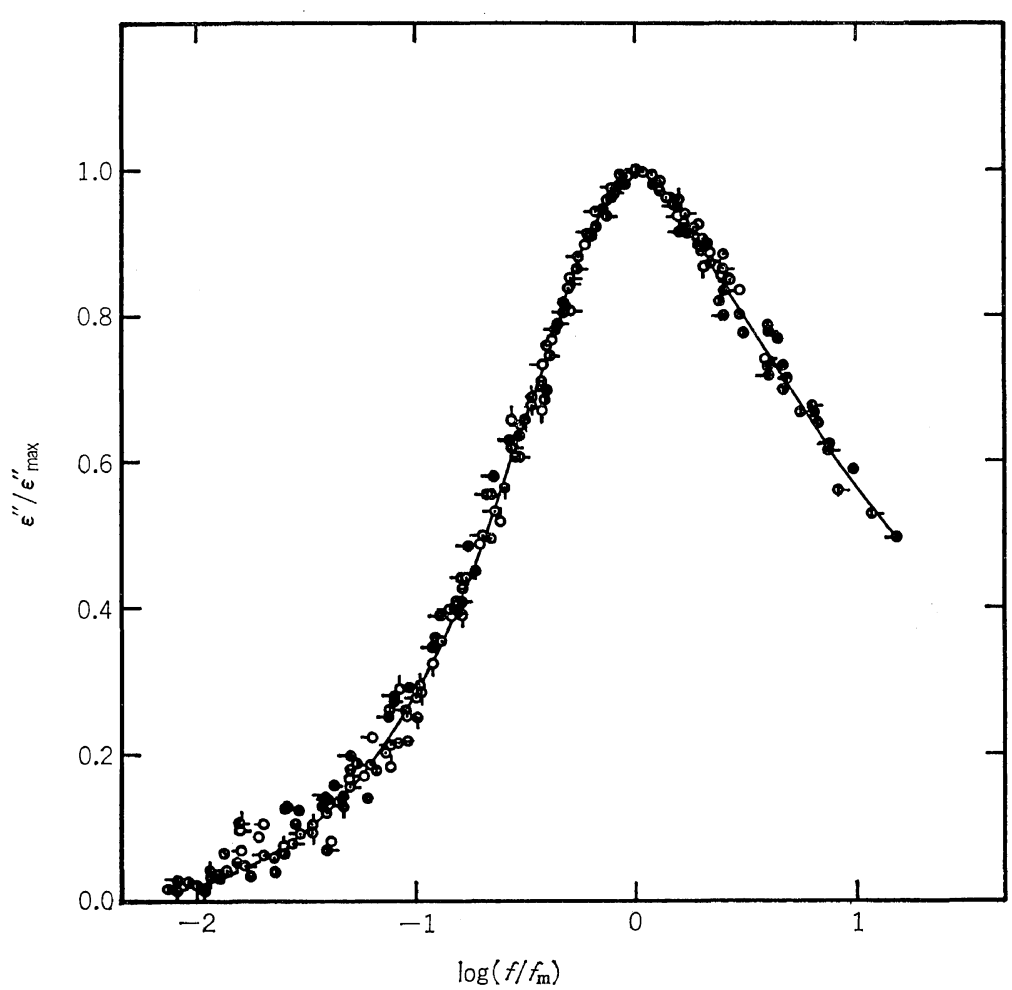

Figure 2. Master plots of $\varepsilon^{\prime \prime} / \varepsilon_{\max }^{\prime \prime}$ against $\log \left(f / f_{m}\right)$ for each polymer solution: $\bigcirc$, PVC in dioxane, $\bar{M}_{n}=0.63 \times 10^{4}, 0.82 \%, 23^{\circ}, 35^{\circ}, 40^{\circ} \mathrm{C} ; \bigcirc^{-}, \bar{M}_{n}=1.3 \times 10^{4}, 1.50 \%, 20^{\circ}$, $30^{\circ} \mathrm{C} ;-\bigcirc, \bar{M}_{n}=2.5 \times 10^{4}, 1.77 \%, 23^{\circ}, 30^{\circ}, 40^{\circ} \mathrm{C} ; \stackrel{\bigcirc}{\bigcirc}, \bar{M}_{n}=4.4 \times 10^{4}, 1.79 \%, 20^{\circ}, 40^{\circ}, 60^{\circ} \mathrm{C}$;

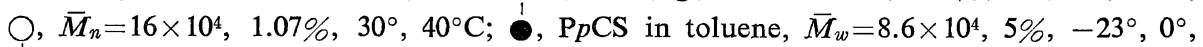
$23^{\circ}, 40^{\circ}, 60^{\circ} \mathrm{C} ; \bullet, \bar{M}_{w}=47 \times 10^{4}, 4.95 \%, 23^{\circ}, 40^{\circ}, 60^{\circ} \mathrm{C} ;-\mathrm{P} p \mathrm{CS}$ in dioxane, $\bar{M}_{w}=$ $8.6 \times 10^{4}, 2.09 \%, 30^{\circ}, 40^{\circ}, 55^{\circ} \mathrm{C}$; (1), PpBS in toluene, $2.20 \%, 24^{\circ}, 40^{\circ}, 60^{\circ} \mathrm{C}$; (1)-, PpBS in dioxane, $2.17 \%, 24^{\circ}, 35^{\circ}, 50^{\circ} \mathrm{C}$; $\odot$, PVAc in toluene, $\bar{M}_{n}=0.79 \times 10^{4}, 5 \%, 0^{\circ}, 23^{\circ} \mathrm{C}$; $\odot-, \bar{M}_{n}=0.97 \times 10^{4}, 5 \%,-13^{\circ}, 0^{\circ}, 23^{\circ} \mathrm{C} ;-\odot, \bar{M}_{n}=3.04 \times 10^{4}, 5 \%, 0^{\circ}, 10^{\circ}, 23^{\circ}, 35^{\circ} \mathrm{C}$; $\odot$, $\bar{M}_{n}=10.97 \times 10^{4}, 5 \%, 23^{\circ} \mathrm{C} ; \odot, \bar{M}_{n}=16.34 \times 10^{4}, 5 \%, 23^{\circ} \mathrm{C} ; \ominus$, PVAc in dioxane, $\bar{M}_{n}=$ $0.97 \times 10^{4}, 4.33 \%, 15^{\circ}, 30^{\circ}, 37^{\circ} \mathrm{C}$; $\ominus$, PVAc in carbon tetrachloride, $\bar{M}_{n}=0.97 \times 10^{4}$, $2.05 \%, 23^{\circ}, 35^{\circ}, 50^{\circ} \mathrm{C}$.

obtained from a plot of $\log f_{m}$ against the reciprocal of the absolute temperature $1 / T$, which gave a straight line. Dependence of $\Delta H_{\mathrm{A}}$ on the molecular weight is small.

The value of $\varepsilon_{\max }^{\prime \prime}$ slightly decreases, linearly with $1 / T$, as the temperature rises and there is a corresponding decrease in $\varepsilon_{0}{ }^{\prime}-\varepsilon_{\infty}{ }^{\prime}$. Thus, the dipole moment remains approximately constant as the temperature changes. ${ }^{9}$ Furthermore, the dependence of $\varepsilon_{\max }^{\prime \prime} /$ concn on the molecular weight is slight, meaning that the dipole moment for a repeat unit is almost independent of the molecular weight.
Two features are observed in the effect of the solvent. One is the definite dependence of the relaxation time on solvent viscosity. The value of the ratio of the relaxation time to the solvent viscosity $\eta_{0}$ is given in Table $V$. It is interesting to note that the ratio for various solutions is approximately constant for each polymer. This observation indicates that the relaxation time is approximately proportional to the solvent viscosity, with a different proportionality constant for each polymer species. The proportionality constant depends only on the polymer species.

The other feature is the relation between the 
S. Mashimo and A. Chiba

Table I. Poly(vinyl chloride) in dioxane

\begin{tabular}{|c|c|c|c|c|c|c|}
\hline $\bar{M}_{n} \times 10^{-4}$ & Concn, $\%$ & Temp, ${ }^{\circ} \mathrm{C}$ & $\varepsilon_{\max }^{\prime \prime}$ & $\varepsilon_{\max }^{\prime \prime} /$ concn & $\log f_{m}, \mathrm{~Hz}$ & $\Delta H_{\mathrm{A}}, \mathrm{kcal} / \mathrm{mol}$ \\
\hline 0.63 & 0.82 & $\begin{array}{l}23 \\
35 \\
40\end{array}$ & $\begin{array}{l}0.0134 \\
0.0129 \\
0.0129\end{array}$ & $\begin{array}{l}1.63 \\
1.57 \\
1.57\end{array}$ & $\left.\begin{array}{l}7.71 \\
7.85 \\
7.90\end{array}\right\}$ & 5.0 \\
\hline 1.3 & 1.50 & $\begin{array}{l}12 \\
20 \\
35\end{array}$ & $\begin{array}{l}0.0249 \\
0.0247 \\
0.0238\end{array}$ & $\begin{array}{l}1.66 \\
1.65 \\
1.59\end{array}$ & $\left.\begin{array}{l}7.45 \\
7.60 \\
7.78\end{array}\right\}$ & 5.2 \\
\hline 2.5 & 1.77 & $\begin{array}{l}15 \\
23 \\
30 \\
40\end{array}$ & $\begin{array}{l}0.0309 \\
0.0305 \\
0.0300 \\
0.0288\end{array}$ & $\begin{array}{l}1.75 \\
1.72 \\
1.69 \\
1.63\end{array}$ & $\left.\begin{array}{l}7.59 \\
7.70 \\
7.79 \\
7.90\end{array}\right\}$ & 5.0 \\
\hline 4.4 & 1.79 & $\begin{array}{l}12 \\
20 \\
40 \\
60\end{array}$ & $\begin{array}{l}0.0315 \\
0.0311 \\
0.0292 \\
0.0280\end{array}$ & $\begin{array}{l}1.76 \\
1.74 \\
1.63 \\
1.57\end{array}$ & $\left.\begin{array}{l}7.45 \\
7.60 \\
7.82 \\
8.05\end{array}\right\}$ & 5.2 \\
\hline 16 & 1.07 & $\begin{array}{l}30 \\
40\end{array}$ & $\begin{array}{l}0.0186 \\
0.0178\end{array}$ & $\begin{array}{l}1.74 \\
1.66\end{array}$ & $\left.\begin{array}{l}7.79 \\
7.90\end{array}\right\}$ & 5.0 \\
\hline
\end{tabular}

Table II. Poly(p-chlorostyrene) in toluene and dioxane

\begin{tabular}{|c|c|c|c|c|c|c|c|}
\hline Solvent & $\bar{M}_{w} \times 10^{-4}$ & Concn, $\%$ & Temp, ${ }^{\circ} \mathrm{C}$ & $\varepsilon_{\max }^{\prime \prime}$ & $\varepsilon_{\max }^{\prime \prime} /$ concn & $\log f_{m}, \mathrm{~Hz}$ & $\Delta H_{\mathrm{A}}, \mathrm{kcal} / \mathrm{mol}$ \\
\hline \multirow[t]{2}{*}{ Toluene } & 8.6 & 5.00 & $\begin{array}{r}-23 \\
0 \\
23 \\
40 \\
60\end{array}$ & $\begin{array}{l}0.0299 \\
0.0275 \\
0.0253 \\
0.0247 \\
0.0235\end{array}$ & $\begin{array}{l}0.598 \\
0.550 \\
0.506 \\
0.494 \\
0.470\end{array}$ & $\left.\begin{array}{l}6.77 \\
7.14 \\
7.40 \\
7.60 \\
7.80\end{array}\right\}$ & 4.8 \\
\hline & 47 & 4.95 & $\begin{array}{l}23 \\
40 \\
60\end{array}$ & $\begin{array}{l}0.0251 \\
0.0247 \\
0.0234\end{array}$ & $\begin{array}{l}0.507 \\
0.498 \\
0.473\end{array}$ & $\left.\begin{array}{l}7.38 \\
7.60 \\
7.80\end{array}\right\}$ & 4.9 \\
\hline Dioxane & 8.6 & 2.09 & $\begin{array}{l}30 \\
40 \\
55\end{array}$ & $\begin{array}{l}0.0114 \\
0.0111 \\
0.0107\end{array}$ & $\begin{array}{l}0.546 \\
0.531 \\
0.512\end{array}$ & $\left.\begin{array}{l}7.20 \\
7.33 \\
7.53\end{array}\right\}$ & 5.9 \\
\hline
\end{tabular}

Table III. Poly(p-bromostyrene) in toluene and dioxane

\begin{tabular}{|c|c|c|c|c|c|c|}
\hline Solvent & Concn, $\%$ & Temp, ${ }^{\circ} \mathrm{C}$ & $\varepsilon_{\max }^{\prime \prime}$ & $\varepsilon_{\max }^{\prime \prime} /$ concn & $\log f_{m}, \mathrm{~Hz}$ & $\Delta H_{\mathrm{A}}, \mathrm{kcal} / \mathrm{mol}$ \\
\hline Toluene & 2.20 & $\begin{array}{l}24 \\
40 \\
60\end{array}$ & $\begin{array}{l}0.0095 \\
0.0085 \\
0.0080\end{array}$ & $\begin{array}{l}0.43 \\
0.39 \\
0.36\end{array}$ & $\left.\begin{array}{l}7.39 \\
7.52 \\
7.64\end{array}\right\}$ & 3.2 \\
\hline Dioxane & 2.17 & $\begin{array}{l}24 \\
35 \\
50\end{array}$ & $\begin{array}{l}0.0100 \\
0.0097 \\
0.0094\end{array}$ & $\begin{array}{l}0.46 \\
0.45 \\
0.43\end{array}$ & $\left.\begin{array}{l}7.14 \\
7.26 \\
7.40\end{array}\right\}$ & 4.3 \\
\hline
\end{tabular}

activation energy for the solvent viscosity, $\Delta H_{\eta}$, and the activation energy for the dielectric relaxation process, $\Delta H_{\mathrm{A}}$. It can be noted that the two activation energies are connected by

$$
\Delta H_{\mathrm{A}}=\Delta H_{\eta}+C
$$

where $C$ is a constant which is independent of the kind of solvent, concentration, and the molecular weight of the polymer, and depends only on the polymer species. Values of $\Delta H_{\mathrm{A}}$ are listed in Tables I-IV. The value of $\Delta H_{\eta}$ is $2.1,3.0$, and $2.6 \mathrm{kcal} / \mathrm{mol}$ for toluene, dioxane, and carbon tetrachloride, respectively, as determined from the slope of the plot of $\log \eta_{0}$ against $1 / T$. The value of $C$ was determined from eq 1 to be 2.1, 2.8, 1.2 , and $1.6 \mathrm{kcal} / \mathrm{mol}$ for PVC, $\mathrm{P} p \mathrm{CS}, \mathrm{P} p \mathrm{BS}$, and PVAc, respectively. 
Dielectric Behaviour of Polymers in Solution

Table IV. Poly(vinyl acetate) in toluene, dioxane, and carbon tetrachloride

\begin{tabular}{|c|c|c|c|c|c|c|c|}
\hline Solvent & $\bar{M}_{n} \times 10^{-4}$ & Concn, $\%$ & Temp, ${ }^{\circ} \mathrm{C}$ & $\varepsilon_{\max }^{\prime \prime}$ & $\varepsilon_{\max }^{\prime \prime} /$ concn & $\log f_{m}, \mathrm{~Hz}$ & $\Delta H_{\mathrm{A}}, \mathrm{kcal} / \mathrm{mol}$ \\
\hline \multirow[t]{5}{*}{ Toluene } & 0.79 & 5.00 & $\begin{array}{r}0 \\
23\end{array}$ & $\begin{array}{l}0.0568 \\
0.0481\end{array}$ & $\begin{array}{l}1.14 \\
0.963\end{array}$ & $\left.\begin{array}{l}7.87 \\
8.09\end{array}\right\}$ & 3.6 \\
\hline & 0.97 & 5.00 & $\begin{array}{r}-13 \\
0 \\
23\end{array}$ & $\begin{array}{l}0.0586 \\
0.0565 \\
0.0490\end{array}$ & $\begin{array}{l}1.17 \\
1.13 \\
0.980\end{array}$ & $\left.\begin{array}{l}7.68 \\
7.82 \\
8.05\end{array}\right\}$ & 3.6 \\
\hline & 3.04 & 5.00 & $\begin{array}{r}0 \\
10 \\
23 \\
35\end{array}$ & $\begin{array}{l}0.0565 \\
0.0528 \\
0.0490 \\
0.0460\end{array}$ & $\begin{array}{l}1.13 \\
1.06 \\
0.980 \\
0.920\end{array}$ & $\left.\begin{array}{l}7.76 \\
7.87 \\
8.00 \\
8.10\end{array}\right\}$ & 3.7 \\
\hline & 10.97 & 5.00 & $\begin{array}{r}0 \\
23\end{array}$ & $\begin{array}{l}0.0563 \\
0.0490\end{array}$ & $\begin{array}{l}1.13 \\
0.980\end{array}$ & $\left.\begin{array}{l}7.72 \\
7.95\end{array}\right\}$ & 3.8 \\
\hline & 16.34 & 5.00 & $\begin{array}{r}0 \\
23\end{array}$ & $\begin{array}{l}0.0563 \\
0.0490\end{array}$ & $\begin{array}{l}1.13 \\
0.980\end{array}$ & $\left.\begin{array}{l}7.72 \\
7.95\end{array}\right\}$ & 3.8 \\
\hline Dioxane & 0.97 & 4.33 & $\begin{array}{l}15 \\
30 \\
37\end{array}$ & $\begin{array}{l}0.0520 \\
0.0475 \\
0.0463\end{array}$ & $\begin{array}{l}1.20 \\
1.10 \\
1.07\end{array}$ & $\left.\begin{array}{l}7.80 \\
7.98 \\
8.06\end{array}\right\}$ & 4.7 \\
\hline $\begin{array}{l}\text { Carbon } \\
\text { tetra- } \\
\text { chloride }\end{array}$ & 0.97 & 2.05 & $\begin{array}{l}23 \\
35 \\
50\end{array}$ & $\begin{array}{l}0.0365 \\
0.0344 \\
0.0313\end{array}$ & $\begin{array}{l}1.78 \\
1.68 \\
1.53\end{array}$ & $\left.\begin{array}{l}7.77 \\
7.89 \\
8.03\end{array}\right\}$ & 4.2 \\
\hline
\end{tabular}

Table V. Ratio of the observed relaxation time $\tau_{\text {soln }}$ to the solvent viscosity $\eta_{0}$

\begin{tabular}{lcccc}
\hline & & \multicolumn{3}{c}{$\tau_{\mathrm{soln}} / \eta_{0} \times 10^{6}$, sec poise ${ }^{-1}$} \\
\cline { 3 - 5 } Polymer & ${ }^{\circ} \mathrm{C}$ C & Toluene & Dioxane & $\begin{array}{c}\text { Carbon } \\
\text { tetrachloride }\end{array}$ \\
\hline PpCS & 40 & 8.5 & 8.3 & \\
PpBS & 24 & 11 & 10 & \\
PVAc & 23 & 2.6 & $1.7^{\mathrm{a}}$ & 2.9 \\
\hline
\end{tabular}

a Relaxation time of PVAc in dioxane at $23^{\circ} \mathrm{C}$ was estimated from the plot of $\log f_{m}$ against $1 / T$.

\section{DISCUSSION}

PVC, $\mathrm{P} p \mathrm{CS}$, and $\mathrm{P} p \mathrm{BS}$ have only one dipole component, perpendicular to the chain backbone, but PVAc has two dipole components, the first one perpendicular to the chain backbone and the second one perpendicular to the first component and attached to a flexible side group with one or more bonds permitting internal rotation. ${ }^{3}$ The dielectric behaviour, however, was the same as that of three other polymers, i.e., PVC, PpCS, and $\mathrm{P} p \mathrm{BS}$. The behaviour of PVAc is interpreted by assuming that the magnitude of absorption due to motion of the perpendicular component is far larger than that of absorption due to internal rotation of the side group. This assumption is supported by studies on solid PVAc. ${ }^{10,11}$ PVAc will, therefore, be treated as a polymer whose dipole is rigidly and perpendicularly attached to the chain backbone.

A molecular-weight-independent relaxation time was observed in solutions of PVC in dioxane, PpCS in toluene, and PVAc in toluene. The same feature was reported on poly(ethylene oxide) in benzene, ${ }^{12} \mathrm{PpCS}$ in benzene, ${ }^{3}$ and PVAc of rather high molecular weight (above $2.2 \times 10^{5}$ ) in toluene. ${ }^{13}$ Stockmayer ${ }^{3}$ proposed that the relaxation time of polymers with dipoles rigidly and perpendicularly attached to the chain backbone will not depend on the molecular weight. Our results offer a strong support to Stockmayer's proposal.

The observed shape of the absorption curve does not depend on the molecular weight, meaning that the distribution of relaxation times is independent of the molecular weight in the molecular-weight range of the polymers used. From this observation and the molecular-weight-independent relaxation time, it may be concluded that the dipolar relaxation mechanism is not affected by the molecular weight, and that the observed dielectric absorption should be attributed to a localized motion of the main chain.

The shape of the absorption curve is asymmetric, being broader on the high frequency side, and does not vary as temperature rises. This fact suggests that the dipolar relaxation mechanism cannot be interpreted by taking into account 
only the transition of dipoles over energy barriers for local conformational change. According to the site model, ${ }^{1,2}$ when the dielectric absorption is caused by the transition of a dipole between different sites, asymmetry of the shape of the absorption curve means that the number of sites are more than three and at least two of them have different potential energies. If this is the case, the shape of the curve should vary as temperature rises. ${ }^{1,2}$ This is not observed in the present investigation.

Two features mentioned above as solvent effects indicate that the viscosity of the medium plays an important role in reorientating the dipole. The dipolar relaxation mechanism, however, cannot be interpreted by taking only the effect of the solvent viscosity into account. The viscosity is related to the frictional coefficient for segmental rotation and the value of $C$ in eq 1 is not so small as to be neglected.

Davies and Stockmayer ${ }^{3}$ have previously found that $\mathrm{P} p \mathrm{CS}$ in $o$-terphenyl, which is a highly viscous solvent, exhibits dielectric absorption in a very low frequency region compared with $\mathrm{P} p \mathrm{CS}$ in benzene. No discussion is given, however, concerning the effect of the solvent viscosity in their paper.

According to Kramers' theory ${ }^{14,15}$ of rate constants for the transition of a single particle over a potential barrier in a viscous medium, the activation energy for the Brownian motion is the sum of the barrier energy and the activation energy for the frictional coefficient, when the friction is sufficiently high and overdamps oscillatory motions. The activation energy for the motion coincides with the barrier energy in the converse case.

Recently Helfand ${ }^{15}$ extended Kramers' theory to polymer problems, and derived an expression for the rate constant of conformational transition, according to which the rate constant does not depend on the molecular weight when the transition is due to the crankshaft motion ${ }^{16,17}$ or to a transition in which the chains next to a given unit are merely translated when the conformational alterration occurs in that unit.

If the Helfand consideration is applied to the present case, the value of $C$ in eq 1 should have the following physical meaning. When the friction is sufficiently high, the rate constant of conformational transition, $\omega$, is expressed by

$$
\omega \propto \mathrm{e}^{-E / k T} / \xi
$$

where $E$ is the energy barrier for the local conformational change in the chain backbone and $\xi$ is the frictional coefficient. If, now, Stokes law is applied to the frictional coefficient, the relaxation time for the motion of the unit, $\tau$, which is the reciprocal of the rate constant, will be given by

$$
\tau=1 / \omega \propto \eta_{0} \mathrm{e}^{E / k T} \propto \mathrm{e}^{\Delta H_{\eta} / k T} \cdot \mathrm{e}^{E / k T}
$$

The relaxation time, then, is proportional to the solvent viscosity $\eta_{0}$. The ratio of $\tau$ observed to $\eta_{0}$ is given in Table $V$. The fact that the ratio $\tau / \eta_{0}$ is constant means that the proportionality constant in eq 3 does not depend on solvent.

The activation energy for the relaxation process is the sum of the activation energy for the solvent viscosity and the energy barrier for the local conformational change in the chain backbone. The value of $C$, then, should represent the value of $E$. In the case of our polymer solutions the friction is reasonably assumed to be sufficiently high. The value of $C$ is, therefore, proposed to represent the energy barrier for local conformational change in the main chain.

Recently Baysal, et al. ${ }^{4}$ investigated dielectric absorption in dilute solutions of $\mathrm{P} p \mathrm{CS}$, $\operatorname{poly}(p$ fluorostyrene), or styrene/4-vinyl-pyridine copolymer in toluene or benzene in the frequency range of $3-50 \mathrm{MHz}$ and in the temperature range of $-10^{\circ}-30^{\circ} \mathrm{C}$, and reported that the apparent activation energy is about $5 \mathrm{kcal} / \mathrm{mol}$ in all cases and that the shape of the absorption curve is symmetric, with $H_{m}=0.39 \pm 0.02$. The relaxation time and the activation energy for $\mathrm{P} p \mathrm{CS}$ in toluene are in complete agreement with our results. The shape of the absorption curve observed in our experiment, however, is asymmetric. This discrepancy may have occurred because their measurements were not extended to sufficiently high frequencies. Baysal, et al., briefly discussed the effect of the solvent viscosity on the dielectric relaxation time.

Besides the dielectric measurements described above, Miyahara, et al. ${ }^{18}$ and Bauer, et al. ${ }^{10}$ measured ultrasonic relaxation in moderately dilute polystyrene solutions in toluene, decaline, ethyl methyl ketone, carbon tetrachloride, and 
benzene in order to investigate the local mode of the chain motion. They interpreted their results in terms of the crankshaft motion, assuming a three-site model. The value of the barrier heights for conformational transition observed by Miyahara, et al., or Bauer, et al., are very different from ours. This discrepancy may have occured because they treated the relaxation mechanism by taking only the site model into account.

A number of theories have hitherto been presented concerning the dielectric relaxation time and the shape of the absorption curve, but none of them seems to explain our experimental results in a satisfactory manner.

Kirkwood and Fuoss ${ }^{8}$ achieved a reasonable order of breadth for the absorption curve, but the shape of the absorption curve they obtained was symmetrical and the frequency of the maximum loss varied with the degree pf polymerization. The observed shape of our absorption curve is asymmetric and the frequency of maximum loss does not depend on the degree of polymerization, as described above. Van Beek and Hermans ${ }^{20}$ and also Tanabe and Okano, ${ }^{21}$ who treated the problem by the spring-bead model, showed that a frequency of maximum loss which does not depend on the degree of polymerization can be obtained, but the shape of the absorption curve derived was Debye-type. Work and Fujita ${ }^{22}$ introduced a correlation length between dipolar reorientations, and derived a nonsymmetrical absorption curve. The theoretical curve, however, was very different from that of our observation.

Clark and $\mathrm{Zimm}^{23}$ have recently discussed dielectric dispersion of a linear chain with dipoles perpendicular to the polymer chain axis by using a linear mechanical model consisting of a chain of torsional springs, dashpots, and beads bearing dipoles. The shape of the absorption curve calculated depended greatly on correlation length, which is a measure of the extent to which rotational motion was correlated along the chain. It was possible to obtain a reasonable shape of the absorption curve if appropriate values are assigned to several parameters. It was also possible to obtain relaxation times which do not depend on molecular weight.

Yamafuji and Ishida ${ }^{24}$ treated the rotational diffusion of dipoles perpendicular to the chain axis, introducing both intrachain and interchain interactions. They succeeded in deriving not only the correct order of breadth but also the correct order of asymmetry of the shape of the absorption curve. Moreover, the relaxation time derived did not depend on the molecular weight. The relaxation times derived from the above two theories, i.e., those of Clark and Zimm, and Yamafuji and Ishida, were both proportional to the frictional coefficient of the diffusing entity, and hence to the viscosity of the solvent in the Stokes law formalism. Thus, these two theories were successful in obtaining molecular-weightindependent relaxation times and the asymmetrical shape of the absorption curve, but they do not give any information on the value of $C$ in eq 1 . Our experimental results suggests that the transition of dipoles over energy barriers for local conformational change in the main chain plays an important role in reorientation of the dipole and that this effect is reflected in the value of $C$ observed. Therefore, an advance in theory which takes into account not only the frictional coefficient for dipole rotation but also the transition over the energy barrier for a local conformational change in the main chain is much to be desired.

Acknowledgement. We wish to thank Professor K. Shinohara and Dr. Y. Hama of Waseda University for their helpful discussions and critical readings of the manuscript.

\section{REFERENCES}

1. J. D. Hoffman and H. G. Pfeiffer, J. Chem. Phys., 22, 132 (1954).

2. J. D. Hoffman, ibid., 23, 1331 (1955).

3. W. H. Stockmayer, Pure Appl. Chem., 15539 (1967).

4. F. E. Karasz, Ed., "Dielectric Properties of Polymers," Plenum Press, New York N.Y., 1972, pp 329-341.

5. A. Kotera, T. Saito, H. Matsuda, and R. Kamata, Repts. Progr. Polymer Phys. Japan, 3, 51 (1960).

6. G. Ciampa and Schwindt, Makromol. Chem., 18-19, 151 (1955).

7. S. Okamoto, Kobunshi (High Polymers, Japan), 17, 1092 (1968).

8. J. G. Kirkwood and R. M. Fuoss, J. Chem. Phys., 9, 329 (1941).

9. L. Onsager, J. Amer. Chem. Soc., 581486 (1936). 
10. Y. Ishida, M. Matsuo, and K. Yamafuji, Kolloid-Z., 180, 108 (1962).

11. Y. Ishida and K. Yamafuji, ibid., 17797 (1961).

12. M. Davies, G. Williams, and G. D. Loveluck, Z. Electrochem., 64, 575 (1960).

13. L. De Brouckere, D. Buess, and L. K. H. Van Beek, J. Polym. Sci., 23, 233 (1957).

14. H. A. Kramers, Physica, 7, 284 (1940).

15. E. Helfand, J. Chem. Phys., 54, 4651 (1971).

16. T. F. Schatzki, J. Polym. Sci., 57, 496 (1962).

17. R. F. Boyer, Rubber Rev., 34, 1303 (1963).

18. H. Nomura, S. Kato, and Y. Miyahara, Nippon Kagaku Zasshi, 90, 1218 (1969); 91, 837 (1970); 91, 1042 (1970).
19. H. J. Bauer, H. Hassler, and M. Immendorfer, Disc. Faraday Soc., 49, 238 (1970).

20. L. K. H. Van Beek and J. J. Hermans, J. Polym. Sci., 23, 211 (1957).

21. Y. Tanabe and K. Okano, Oyo Buturi, 38, 377 (1969).

22. R. N. Work and S. Fujita, J. Chem. Phys., 43, 3779 (1966).

23. F. E. Karasz, Ed., "Dielectric Properties of Polymers," Plenum Press, New York, N.Y., 1972, pp 45-97.

24. K. Yamafuji and Y. Ishida, Kolloid-Z., 183, 15 (1962). 